CLINICAL ETHICS

\title{
An antidote to the emerging two tier organ donation policy in Canada: the Public Cadaveric Organ Donation Program
}

\section{s Giles}

J Med Ethics 2005;31:188-191. doi: 10.1136/jme.2003.002931

In Canada, as in many other countries, there exists an organ procurement/donation crisis. This paper reviews some of the most common kidney procurement and allocation programmes, analyses them in terms of public and private administration, and argues that privately administered living donor models are an inequitable stopgap measure, the good intentions of which are misplaced and opportunistic. Focusing on how to improve the publicly administered equitable cadaveric donation programme, and at the same time offering one possible explanation for its current failure, it is suggested that the simple moral principle of "give and you shall receive", already considered by some, be extended further. This would allow for those who are willing to sign up to be a public cadaveric donor be given a priority for receiving an organ donation should they ever require it. It is argued that this priority may provide the motivation to give that is so far lacking in Canada. This model is called the Public Cadaveric Organ Donation Program.

M uch has been written about kidney procurement and allocation programmes and the increasing gap between the availability of kidneys for transplant and the need for them. ${ }^{1-4}$ In addition to the good news that there has been a "gradual increase in the donor rate", data also show that "donor programs are maximizing the number of organs retrieved and transplanted from cadaveric donors". ${ }^{5}$

However, despite that good news, in Canada the rate of transplants has not kept pace with the growing transplant waiting list, with kidney transplants representing nearly $80 \%$ of all patients on the Canadian transplant waiting list. ${ }^{5}$ Consequently a national coordinated and comprehensive strategy was proposed by Health Canada to overcome the poor donation rate. ${ }^{6}$ However as of spring 2003 this strategy still has not been implemented. In 2000, Ontario acknowledged the crisis and, acting alone, introduced new legislation establishing a new governmental agency, with the goal of doubling organ transplants in five years. The Ontario government hopes to do this by "maximizing donor opportunities, in order to increase the number of donors for organ and tissue donation". ${ }^{7}$

In British Columbia, the average wait for an adult cadaveric kidney transplant in 2001 was 50.1 months, up from an average wait of 28 months in 1997. ${ }^{8}$ Cecka notes, "until cadaveric kidney donation rates increase, living unrelated kidney donation represents an important alternative to dialysis". ${ }^{\prime}$ As a result of the growing crisis in the shortage of organs for donation, new donor models have been developed in an attempt to expand the donor pool. In Ontario the percentage transplants from living donors has steadily and dramatically risen from $19 \%$ in 1990 to $76 \%$ in 1999. ${ }^{10}$ Additionally, Toronto General Hospital in Ontario is "currently expanding the living donor transplant program". ${ }^{11}$
However, the expansion of the donor pool is the result of many factors that include medical advances along with pragmatism, both of which are underpinned by a sense of extreme urgency. When combined, these factors are forcing an ad hoc policy that is lacking foresight. Thus it is time for an evaluation of where we are at this point in organ donation policy, and ask the question: is this where we want to go?

\section{PUBLIC AND PRIVATE DONOR MODELS}

Many models have been developed to collect and allocate available kidneys for transplant. I shall argue that they can be divided into private and public models. Traditionally the distinction between private and public programmes is based on the premise of which party pays for the service. If the government pays for the service then it is a public programme, whereas if the individual pays for the service it is considered private. With regards to kidney transplants, the cadaveric waiting list is a public service as the government fully insures its costs. In the cadaveric donation and living donation programmes the cost of the transplant medical services will be covered for both the donor and the recipient. The living donor programme is a somewhat more complex than the cadaveric programme however. For example, on occasion the recipient has a living donor who lives in another country; the cost of that person's travel to Canada and all related expenses will not be covered. In addition to air travel, these expenses may include loss of earnings, meals, and accommodation-not to mention possible associated health risks. Beyond these large financial costs, there is also a requirement for social capital: there has to be someone who is willing to be a donor. As a result, Canada has both a public cadaveric donor programme that is fully insured requiring no private funds and a living donor programme which may or may not require private financial resources and will definitely require private social resources.

In Canada there is currently only one kind of fully public programme: the Cadaveric Donation (CD) programme. In this model the kidney from someone who has passed away, and is not related or known to the recipient, is transplanted into a living recipient. In Canada, this is a provincially run programme, where donors must opt in or give consent to be a cadaveric donor. If they are willing to donate their organs upon death, typically this information is placed on their driver's license or healthcare card. If they do not opt in, or do not give consent, it is then understood that they do not wish to donate their organs. However, final consent goes to the family if they are involved. ${ }^{10}$

When one has no social capital one cannot receive a living donor transplant. If you have the social capital but do not have financial resources, you may also not receive a living

Abbreviations: CD programme, Cadaveric Donation programme; LRD, living related donor; LUD, living unrelated donor; NDD, non-directed donation; PCODP, Public Cadaveric Organ Donation Program; PE, paired exchange. 
donor transplant. In this way living private models are not available to the general public unless they have the social and financial resources. Consequently, it is societies most vulnerable, those who are socially isolated and have limited financial means, who will most likely not receive a living donation.

In the living related donor (LRD) model, the kidney of the living biological relative of the recipient is transplanted from the donor, with the negotiation being made between them. In the living unrelated donor (LUD) model, the possible private donor pool is extended beyond the LRD, to include people such as spouses, close friends, and people who are "emotionally related" to the recipient. Like the LRD model, once again the agreement is negotiated privately between the donor and the recipient. Paired exchange (PE) is also private in nature and is essentially an extension of the LUD model, although its private nature may be extended to include the hospital or possibly others who help find a medical match. Here a person who requires a kidney, and has someone who is willing to donate (whether they are an LRD or LUD) but is not a medical match, is paired with another person who also has a donor who is not a match. The two donor recipient pairs then undergo a simultaneous transplant. ${ }^{12}$

Another interesting model is the non-directed donation (NDD). ${ }^{13}$ This model appears to straddle the private and public divide by having the regional transplant centre offer itself as an intermediary between the donor and recipient. In NDD someone has contacted the transplant unit and offers to donate a kidney to anyone who needs it. In this way, it appears public because the donor and recipient do not initially know each other, although the hospital can make provisions for them to meet later, if they both request it. However, NDD is not public in the sense that the donor has chosen to donate to a certain hospital. Further, the transplant centre does not make the resource available to the general public, but instead maintain the resources as private, for its own patients.

\section{PUBLIC VERSUS PRIVATE Limitations of the donation models}

In Canada, the CD programme's current pool of donors is not large enough to meet growing demands: not enough people are signing up for it. Consequently, as a public programme, it is failing the public. LRD, LUD, and PE, are alternative models developed to address the waiting list problem of the $\mathrm{CD}$ programme. With these models the problem of donor shortage is not addressed on a societal or public level, but is instead being shifted to the individual. That is, if a person has availability of resources on a personal or private levelwhether they have financial or social resources - they will be transplanted sooner. If not they are placed onto the CD programme list, with a waiting time substantially longer than NDD, LRD, LUD, and PE.

As a result, these private models appear to have created an inequitable two tier system-one for those who have social and financial capital, and one for those who do not. Moreover, those who have access to the private programmes also have access to the public programmes: if they cannot locate private resources they can always return to public resources. Now, it may be said that those who leave the public list to pursue private donation programmes will increase the resources for those who are on the public programme. This may or may not be true, but if they return the list then grows. This may cause a fluctuation in waiting times, and deprive those on the list from a predictable wait, thereby increasing the anxiety already experienced by being on the waiting list. However, it is the ability to move between the private and public models which is not equal: the choice to move between the two is a privilege of those who have the resources.

The NDD model is interesting because prima facie it seems to have established a way for a small "public" style, or local programme to be based on an equitable model of distribution. They have tried to establish equity by ruling out donations that are targeted to a particular race or sex, which would appear closer to a private negotiation. It does however differ from the other public programme $(\mathrm{CD})$ in that the donor is living, and that it is not a large-scale public programme. Therein lies the problem. Without being a public programme it has retained elements of selectivity and privacy - that is, the donor may specifically select whom or which kind of person receives the donation, by privately selecting which hospital or region to donate to. This is problematic because hospitals may-and quite often doserve specific socioeconomic, ethnic, and religions populations. Thus donors are still able to choose, to some extent, a target population that is represented by a certain hospital or region. In this way the NDD programme is vulnerable to charges of selection on a macro level. While attempting to rebuff attempts of donor direction, by employing the criteria of non-directed donation, they still must accept that their hospital has been selected by the donor, thereby placing their model closer to the realm of a private rather than public programme.

Consequently all of these models (LRD, LUD, PE, and NDD) have elements of private donor selection. The exception lies with the CD programme, which is the best attempt at a non-directed, public (and therefore equitable) donor programme. Moreover, as public administration is a principle of the Canada Health (1984), models other than the CD programme appear to have run roughshod over the spirit if not the legalities of the act.

\section{Reinvigorating the CD programme}

There is no doubt that there is room for improvement within the CD programme for it to become more efficient with resources. Yet the resolution of the problem will take more than this for, as Hoffenberg states, "the solution lies in increasing the supply". ${ }^{14}$ I would like to argue that the central problem lies outside of the realm of efficiencies and comes down to the plain fact that not enough people are signing up to donate their kidneys after death. Why is this so?

One simple reason I suggest is that people do not see the benefit for themselves in consenting to be a cadaveric donor. That is they receive nothing, or at least not enough, out of such an act. In recognition of this problem, the USA based Organ Procurement and Transplantation Network and the United Network for Organ Sharing has recently endorsed US legislation, which would study incentives for donation. ${ }^{15}$ Among the recommendations are a "medal of honour" and reimbursement for the donors' funerals. Adding weight to the idea of incentives, which still remain solidly symbolic and not financially centred, Delmonico et al have also recognised the limits of altruism and volunteerism. ${ }^{16}$ In doing so they have endorsed incentive based ideas such as (1) the medal of honour, (2) reimbursement for donor's funeral expenses, (3) paired exchanges, (4) medical leave for donation, (5) donor insurance, and (6) ensuring access to organs for previous donors.

The proposal of these incentives is helpful as long are they are considered as ways to protect and improve the existing public programme-CD.

\section{A benefit of giving is receiving}

Perhaps the most interesting incentive offered by Delmonico et al is (6) ensuring access to organs for previous donors. Within the traditional system of allocating points for prioritising donors, 
they suggest, "the need for a transplant in a previous kidney donor should constitute the highest priority in the allocation of organs".

They are suggesting an important moral concept: prioritising transplants to those who have already donated. They seem to be saying that if you are willing to give, then you shall receive, and because of your ability to give, your future potential need shall be given the highest priority. I would like to extend this idea to the general CD programme, but before doing so it is interesting to note that elements of the PE model have also incorporated the idea of if you give you shall receive. That is by giving your kidney to someone else other than your initial intended recipient: if your kidney is not a medical match to your intended initial recipient, your initial intended recipient shall receive a donation from someone else who is a medical match for them. Simplified, it can be stated as this: if you give, your loved one will receive, and by extension so shall you.

Why not say that those who are willing to give and sign up for kidney donation upon their death will receive the benefit of having a priority to receive a kidney transplant if they require one during their lifetime? Acknowledging the limits of altruism and volunteerism, this idea recognises the self motivated desire for giving. Indeed it also offers one explanation for the failure of the CD programme and the rise of other programmes where the benefit is more immediately tangible, as in such cases where people who donate see the recovery of their own loved ones. But the only thing which may be more important than seeing one's loved ones recover, I am suggesting, is knowing that one's gift may actually benefit oneself-by prolonging one's own life. In this way giving, and the receiving of benefits which come from it, can be seen as a self-interested interaction that promotes both one's own wellbeing and that of others.

It seems plausible that many people would immediately see the benefit of signing an organ donation card, knowing that they would receive the benefit of a transplant priority for doing so. Of course, that this personal health benefit would also help others in need would be a factor that in itself may be reason enough for some to donate; for those for whom it would not be enough, the benefit would be a compelling reason to donate to the $\mathrm{CD}$ programme. What of those who did not sign up? Would we have to say that their gamble failed? I do not believe so. Those people who failed to sign up and subsequently found themselves in need of a transplant would still be placed on the waiting list but would be ranked below those who had signed up. However this would not preclude them from accessing the private models available. More importantly, if people were willing to donate but unable to do so for medical reasons or other reasons beyond their control it would not be held against them.

The main principle here is that if you are willing to donate, you will receive priority for transplantation if you should require it. This model is based on the argument that while people are healthy, donation is not appealing - which may offer another reason for the lack of increase in general rates of organ donation. If this model was publicised, people who were not willing to donate to traditional CD programmes may reconsider when they realise that they will not receive preferential treatment.

As a result, it is hypothesised that by increasing the motivation for donation, by connecting the impersonal and distant policy to the personal lives of the public, eventually this policy would increase the pool of donors. One of the impacts of such a policy would be for the general public to realise that they will receive benefit from donation to such an extent that incentives would no longer be required.

Kleinman and Lowy presented support for a model similar to this. ${ }^{17}$ Noting the problematic situation with organ donation back in 1989, they called for a model where adults who were willing to donate would have "priority for receiving organs generated by the program that might be needed at a future date"

More recently, Gubernatis and Kliemt's "Solidarity Model" has also considered the idea of offering a priority to those willing to donate, or those who have already donated, as a way to cope with the rationing problem currently faced in organ transplantation. ${ }^{18}$ They suggest that the existing medical criteria for the allocation algorithm would remain the same, but willingness to donate or previous donation should be an additional factor.

\section{THE PROBLEM WITH PRESUMED CONSENT}

Any discussion of this topic cannot proceed without considering the issue of presumed consent. Presumed consent is the model where people are presumed to have given consent for donation unless they have declared otherwise. This places the onus on the individual to make his or her organ donation wishes known-otherwise it is presumed that their wish is to be a donor. Austria, Belgium, and Spain have adopted this policy, which has been associated with increases in the number of cadaveric organ donors. ${ }^{19}$ Erin and Harris have shown clearly that presumed consent is an affront to informed consent, appropriately labelling it a "fiction". Others have argued that presumed consent collides with the principle of autonomy. ${ }^{16}$

Moustarah has argued for the adoption of presumed consent in Canada. ${ }^{20}$ However, in doing so he acknowledged that it would be a "radical change in policy". That this policy has not been adopted as of 2003, suggests that presumed consent, six years later, is still a radical policy that Canadians are not yet ready to embrace. Currently, in Ontario, families of potential donors are approached for final consent, no matter what the potential donor has indicated. ${ }^{10}$

The Public Cadaveric Organ Donation Program (PCODP) overcomes the ethical problems associated with presumed consent by not being presumptuous about people's wishes. In practice, this means not doing anything unless it is explicitly indicated. Thus family members would not be able to have their wishes override those of the deceased. In doing so the important principles of autonomy and the related concept of consent are retained. Respecting this, in the PCODP people are persuaded that in order to receive a personal health benefit they will have to choose to consent to donation upon their death.

\section{CONCLUSION}

With the introduction of PE, transplant centres are starting to accept the idea that receiving a health benefit from a donation is acceptable. Others have also argued for increased incentive to donate. ${ }^{7}$ Kleinman and Lowy, and Gubernatis and Kliemt have both argued that those who are willing to donate should receive a priority benefit if/when a transplant becomes necessary.

The argument offered here is that the privately administered models of LRD, LUD, PE, and NDD are unjust, and that these models are undermining the public CD programme. Consequently the cadaveric donation programme should be rebuilt. This rebuilt programme would be called the Publicly Administered Cadaveric Donation Model

By building on the concept of ethically acceptable, nonfinancially based incentives to donate, and the equitable nature of a public programme like $\mathrm{CD}$, I have argued for the application of the moral principle "if you give (organs) you shall receive (organs)" within the framework/algorithm of the existing publicly administered $\mathrm{CD}$ programme. If adopted, the PCODP could reinvigorate the existing CD programme, and may overcome public apathy towards it by 
finally giving the general public a compelling reason to donate. This proposal would of course be a solution aimed at the long term and would take time to research, develop, and implement.

\section{Author's affiliation}

Mr S Giles, Toronto General Hospital, University Health Network, 200 Elizabeth Street, Room ESG-470, Toronto, ON Canada M5G 2C4; stephen.giles@uhn.on.ca

Received 2 January 2003

In revised form 30 June 2003

Accepted for publication 4 September 2003

\section{REFERENCES}

1 Beechman, L. BMA wants presumed consent for organ donation. BMJ 1999;319:141.

2 Hauptman PJ, O'Connor KJ. Procurement and allocation of solid organs for transplantation. New Engl J Med 1997;336:422-31.

3 Erin CA, Harris J. Presumed consent or contacting out. J Med Ethics 1999;25:365-6

4 Childress JF. The failure to give: reducing barriers to organ donation. Kennedy Inst Ethics J 2001;11:1-16.

5 Canadian Institute for Health Information. Organ donation rates vary widely across Canada, reports ClHI. Available from http://secure.cihi.ca/cihiweb/ dispPage.jsp?cw_page = media_17apr2002_e (accessed 22 November 2004).

6 Health Canada. Executive summary: a coordinated and comprehensive donation and transplantation strategy for Canada. Available from http:// www.hc-sc.gc.ca/english/protection/biologics_genetics/organ_strategy/ exec_summary.htm (accessed 22 November 2004).

7 Government Relations Committee of the Kidney Foundation of Canada. Ontario update. Toronto, Canada: Kidney Foundation of Canada, 2002

8 British Columbia Transplant Society. Stats and FAQs: Current statistics as of October 10 2002. Available from http://www.transplant.bc.ca/

stats_faqs_main.htm\#currentstats (accessed 22 November 2002)

9 Trillium Gift of Life Network. Statistics. Available from http:// www.giftoflife.on.ca/forefront/flash.cfm (accessed 4 April 2003)

10 Cecka MJ. Kidney transplantation from living donors. Annu Rev Med 2000;51:393-406.

11 Toronto General Hospital, University Health Network. Multi Organ Transplant Program - Future Directions: Available from http:// www.torontotransplant.org/pages/program/future.html laccessed 22 November 2004)

12 Ross LF, Rubin DT, Siegler M, et al. Ethics of paired-kidney-exchange program. New Engl J Med 1997;336:1752-5

13 Matas AJ, Garvey CA, Jacobs CL, et al. Non-directed donation of kidneys from living donors. New Engl J Med 2000;343:433-6.

14 Hoffenberg R. Acquisitions of kidneys for transplantation. In: Levinsky NG, ed. Ethics and the kidney. New York: Oxford University Press, 2001 130-43.

15 The Organ Procurement and Transplantation Network \& The United Network for Organ Sharing. Available from http://www.unos.org/news/ newsDetail.asp?id = 1 (accessed on 22 November 2004).

16 Delmonico FL, Arnold R, Scheper-Hughes N, et al. Ethical incentives-not payment-for organ donation. New Engl J Med 2002;346:2002-5.

17 Kleinman I, Lowy FH. Cadaveric organ donation: ethical considerations for a new approach. Can Med Assoc J 1989:141:107-10.

18 Gubernatis G, Kliemt H. Solidarity model: a way to cope with rationing problems in organ donation. Transpl Int 2000;13:S607-S608.

19 Kennedy I, Sells RA, Daar AS, et al. The case for 'presumed consent' in organ donation. Lancet 1998;351:1650-52.

20 Moustarah F. Organ procurement: let's presume consent. Can Med Assoc $J$ $1998 ; 158: 231-4$.

\section{Call for papers}

The Journal of Medical Ethics is planning to publish a number of thematic issues and invites submissions of original or short papers on the following topics:

Deadline 15 June 2005

Neuroethics

Deadline 15 December 2005

Public Health Ethics

Ethical issues is obstetrics and gynaecology

Multidisciplinary research in medical ethics

\section{Deadline 15 June 2006}

Equity and justice in health care

Ethical issues in oncology and palliative care

Teaching ethics to health care students and professionals

If you would like to discuss a possible submission please e-mail Søren Holm at holms@cardiff.ac.uk with your idea. Prior discussion with the editor is not obligatory.

Please state in your submission letter that you would like the paper considered for a thematic issue. 